\title{
ANALISIS KUALITATIF LOGAM Cd PADA SUNGAI JL. KALIGAWE RAYA
}

\author{
Silvi Rahmawati \\ Program Sarjana Jurusan Kimia Fakultas Sains dan Teknologi UIN Walisongo Semarang \\ Email: silvirahma273@gmail.com
}

\begin{abstract}
s
Sepanjang Jl. Kaligawe Raya terdapat berbagai macam industri, sehingga berpotensi menjadi sumber logam berat Cd yang dapat mencemari sungai yang ada disekitarnya. Penelitian ini bertujuan untuk mengetahui secara kualitatif kandungan logam berat Cd dalam air di sungai yang mengalir di sepanjang Jl. Kaligawe Raya. Penelitian dilaksanakan pada bulan Mei 2018. Metode penelitian adalah studi kasus. Analisis logam Cd dilakukan secara kualitatif dengan menggunakan empat pereaksi yang berbeda.menggunakan Hasil penelitian menunjukkan bahwa sungai tersebut terdeteksi logam berat Cd pada Stasiun 3 sedangkan pada stasiun 1 dan 2 tidak terdeteksi.
\end{abstract}

Kata kunci : Logam Cadmium, Uji Kualitatif,Sungai Jl.Demak-Semarang

\section{Pendahuluan}

Pembangunan industri dapat memberikan dampak positif maupun negatif. Dampak postif yang diberikan adalah dapat menyerap tenaga kerja lebih banyak serta mampu menciptakan nilai tambah yang dapat berpengaruh bagi devisa negara. Dampak negatif yang dihasilkan dapat berpengaruh bagi lingkungan hidup (Nawawi \& dkk, 2015). Limbah industri jika dikelola dengan benar maka tidak akan menimbulkan dampak yang negatif, apabila pelaku pengusaha industri kurang memiliki kepedulian terhadap masyarakat sekitar dan masih adanya keterbatasan dana maka limbah industri tersebut tidak dikelola dengan baik yang akhirnya mengakibatkan kerugian bagi masyarakat (Widiyanto \& dkk, 2015).

Aktivitas perindustrian disekitar wilayah Genuk dikhawatirkan dapat mencemari sungai di Jl.Kaligawe Raya dikarenakan pembuangan limbah secara terus menerus. Keadaan tersebut ditandai dengan terlihatnya perairan yang kotor dan banyak sampah akibat dari buangan limbah dari aktivitas tersebut, termasuk diantaranya buangan limbah logam berat Kadmium (Cd). Pembuangan limbah industry kesungai tanpa ada pengolahan diduga menjadi penyebab tercemarnya sungai dan organisme yang hidup didalamnya.

Kadmium adalah suatu unsur kimia dalam tabel periodik yang memiliki lambang $\mathrm{Cd}$, nomor 
atom 48 dan massa atom standar 112,411(Vogel,1990). Kadmium digunakan dalam industri sebagai bahan dalam pembuatan baterai, pigmen, pelapisan logam dan plastik. Kadmium dan senyawanya bersifat karsinogenik dan bersifat racun.(Darmono,2001). Kadmium merupakan salah satu elemen yang paling berbahaya bagi kesehatan manusia, karena menghasilkan efek buruk pada proses metabolisme .Kadmium di klasifikasikan sebagai unsur yang bersifat toksik dengan waktu paruh pada rentang 10-30 tahun dan dan diketahui dapat membuat kerusakan pada organ seperti ginjal, hati dan paru paru, walau dalam konsentrasi yang sangat kecil (Xiadhong,2011). Cadmium membentuk ikatan baik dengan ligan organik maupun anorganik. seperti $\mathrm{Cd}(\mathrm{OH})+, \mathrm{CdCl}+, \mathrm{CdSO} 4, \mathrm{CdCO} 3$ dan $\mathrm{Cd}$ organik (Sanusi, 2006).

Pemantauan terhadap logam Kadmium (Cd) Disekitar sungai Jl.Kaligawe Raya diantaranya adalah diperairan sayung dilaporkan oleh Endang (2017) bahwa kandungan Cd tidak teridentifikasi disemua stasiun dan kandungan $\mathrm{Cd}$ dalam sedimen berkisar antara 0,51-1,59mg/kg, Sedangkan kandungan logam Cd pada Kerang Hijau (Perna viridis) di Sayung Demak pada kerang ukuran besar berkisar 54,80-364,26mg/kg, kerang ukuran sedang berkisar 21,38103,85mg/kg, dan untuk kerang berukuran kecil berkisar antara 2,22-5,77 mg/kg. penelitian Cd di Sungai Sayung dan Sungai Gonjol, Kabupaten Demak dilaporkan oleh Yulianto et al.(2011) bahwa kandungan Cd dalam air di Sungai Sayung dan Sungai Gonjol Kabupaten Demak mempunyai nilai 0,010-0,190 $\mathrm{mg} / \mathrm{L}$; dalam sedimen 0,340-4,167 mg/kg; dan dalam jaringan lunak kerang darah 2,6383,799 $\mathrm{mg} / \mathrm{kg}$. Pemantauan ini dilaporkan pula oleh Husnan et al. (2012) bahwa di Perairan Wedung, Demak kandungan logam berat $\mathrm{Cd}$ dalam air mempunyai nilai 0,01 ppm,sedangkan pada sedimen berkisar 0,4694-0,7257ppm dan jaringan lunak Kerang Simping berkisar 5,9212-8,0136 ppm.

Jl.Kaligawe Raya adalah daerah yang sering terjadi banjir rob,apabila sungai di kawasan tersebut tercemar logam berat $\mathrm{Cd}$ maka dikhawatirkan logam akan masuk kedalam tubuh melalui pori-pori kulit dan menimbulkan efek bagi kesehatan Mengingat Kadmium dan senyawanya bersifat karsinogenik dan bersifat racun kumulatif, sehingga perlu dilakukan penelitian untuk mengetahui apakah sungai dikawasan di Jl.Kaligawe Raya mengandung logam Cd mengingat potensi pencemar yang sangat banyak didaerah tersebut.

\section{Metode Penelitian}

\section{Alat dan Bahan}

Tabung Reaksi, Rak tabung reaksi, Corong, Pipet tetes, Gelas beker $50 \mathrm{~mL}$. Sampel air sungai di Jl.Kaligawe Raya, Kertas saring, Larutan Natrium Hidroksida $1 \mathrm{M}$, larutan Natrium Sulfida 1 M, Lrutan Ammoniak 1 M, Larutan Na2EDTA dan Pereaksi muroksid-NaCl, $\mathrm{PH}$ universal.

Prosedur Kerja

Sampel diambil dari 3 stasiun disungai sepanjang Jl.Kaligawe Raya masing-masing stasiun diambil 3 sampel, Sampel diambil dengan kedalaman yang sama yaitu $1 \mathrm{M}$ dari permukaan. Sa'at pengambilan sampel dilakukan penyaringan karena air di sungai Jl. Kaligawe Raya berwarna hitam keruh. Sampel disaring sebelum melakukan pengujian.diambil 5 tetes Sampel dan diuji dengan menggunakan reagen Natrium Hidroksida $1 M$, reagen Natrium Sulfida $1 M$, Reagen Ammoniak $1 \mathrm{M}$, Pengompleks Na2EDTA $1 \mathrm{M}$ dan Pereaksi muroksid-NaCl, Masing Sampel direaksikan dengan 5 tetes masing-masing pereaksi. 


\section{Hasil dan Pembahasan}

Sampel yang positif mengandung logam Cd

\begin{tabular}{lllll}
\hline Sampel & $+\mathrm{NaOH}$ & $+\mathrm{NH}_{3}$ & $+\mathrm{Na}_{2} \mathrm{~S}$ & + \\
& & & & $\mathrm{Na}_{2}$ EDTA \\
\hline A1 & - & - & - & - \\
$\mathrm{A} 2$ & - & - & - & - \\
$\mathrm{A} 3$ & - & - & - & - \\
$\mathrm{B} 1$ & - & - & - & - \\
$\mathrm{B} 2$ & - & - & - & - \\
$\mathrm{B} 3$ & - & - & - & - \\
$\mathrm{C} 1$ & + & + & - & + \\
$\mathrm{C} 2$ & + & + & - & - \\
$\mathrm{C} 3$ & + & + & - & + \\
\hline
\end{tabular}

Hasil menunjukan Bahwa Pengujian kualitatif yang pertama dengan menambahkan Natrium Hidroksida $(\mathrm{NaOH}) 1 \mathrm{M}$ pada sampel. Sampel positif mengandung $\mathrm{Cd}$ adalah sampel yang menghasilkan endapan putih karena terbentuknya $\mathrm{Cd}(\mathrm{OH})$.Sampel yang positif mengandung $\mathrm{Cd}$ pada pengujian ini adalah sampel C1,C2 dan C3.

$$
\mathrm{Cd}^{2+}+2 \mathrm{OH}^{-} \rightleftharpoons \mathrm{Cd}(\mathrm{OH})_{2} \downarrow
$$

Pengujian kualitatif yang kedua dilakukan dengan menambahkan ammonia $\left(\mathrm{NH}_{3}\right) 1 \mathrm{M}$ pada sampel. Sampel positif jika menghasilkan endapan putih dan endapan larut jika ditambahkan reagen berlebih. Sampel yang positif mengandung $\mathrm{Cd}$ pada pengujaian ini adalah sampel C1,C2 dan C3.

$\mathrm{Cd}^{2+}+2 \mathrm{NH}_{3}+2 \mathrm{H}_{2} \mathrm{O} \rightleftharpoons \mathrm{Cd}(\mathrm{OH})_{2}+2 \mathrm{NH}_{4}{ }^{+}$

$\mathrm{Cd}(\mathrm{OH})_{2}+4 \mathrm{NH}_{2} \longrightarrow\left[\mathrm{Cd}\left(\mathrm{NH}_{3}\right)_{4}\right]^{2} \neq+2 \mathrm{OH}^{-}$

Pengujian kualitatif yang ketiga dilakukan dengan menambahkan Natrium Sulfida $\left(\mathrm{Na}_{2} \mathrm{~S}\right) 1 \mathrm{M}$ pada sampel.Sampel positif jika menghasilkan endapan kuning. Pada pengujian dengan Natrium Sulfida $\left(\mathrm{Na}_{2} \mathrm{~S}\right)$ 1M tidak ada sampel yang terindikasi positif. Kemungkinan karena reagen
$\mathrm{Na}_{2} \mathrm{~S}$ yang digunakan telah rusak karena kesalahan praktikan kuran menjaga kesterilan dari reagen.

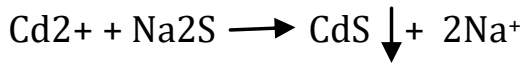

Pengujian sampel yang keempat dengan menambahkan pengompleks $\mathrm{Na}_{2}$ EDTA dan indicator murokside pada sampel pada $\mathrm{pH}=10$. Sampel positif mengandun Cd jika menghasilkan larutan berwarnamerah anggur. Pada pengujian ini terdapat 2 sampel yang positif yaitu sampel C1 dan Sampel C3.
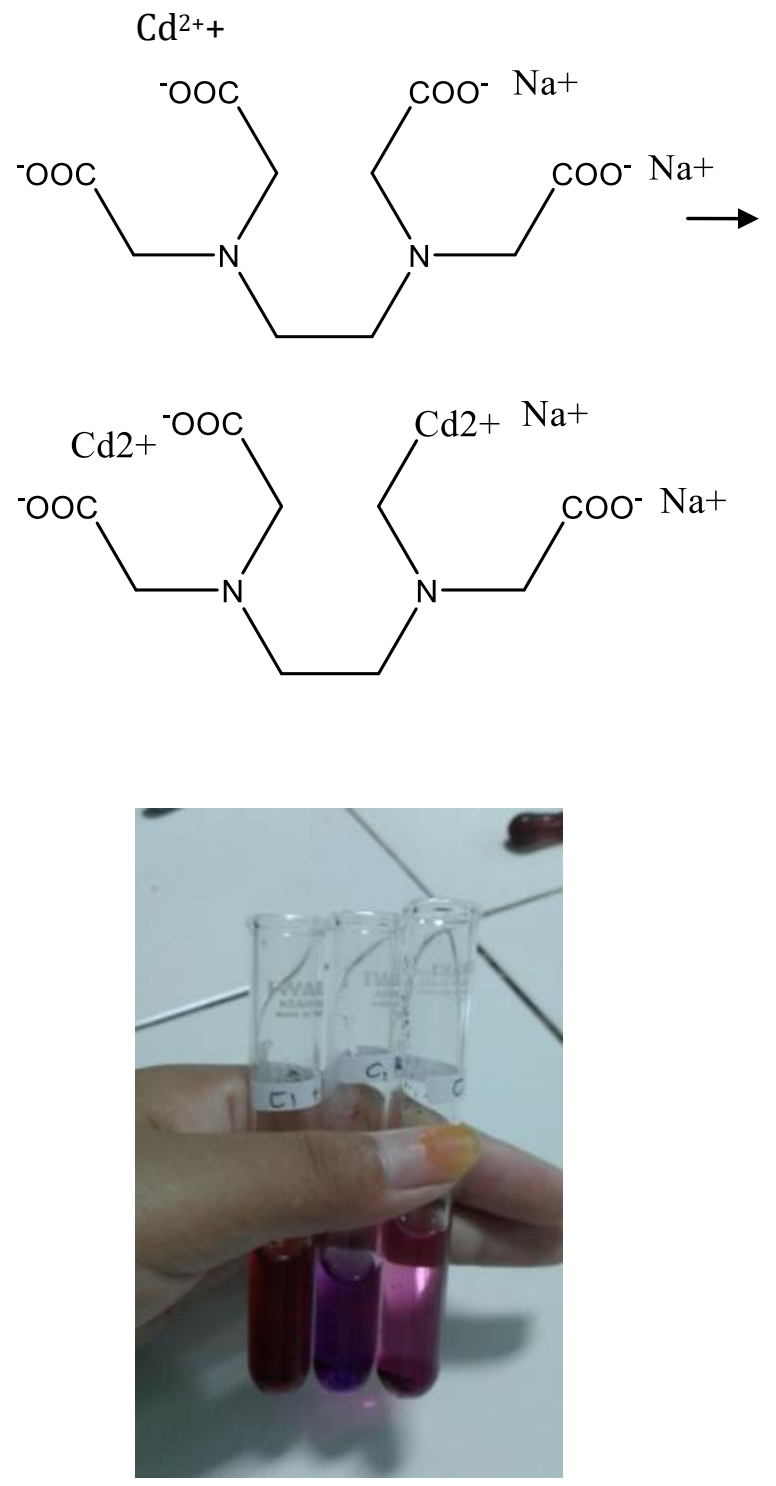
Hal ini menunjukan bahwa logam Cd tidak terdeksi pada stasiun 1 dan stasiun 2 dan hanya terdapat pada stasiun 3. Hal ini dikarenakan pada stasiun 1 dan stasiun 2 adalah daerah pemukiman warga sedangkan pada Stasiun 3 adalah daerah kawasan industry sehingga sungai sudah tercemar oleh limbah industri. pertumbuhan yang sangat cepat di bidang industri sejak tahun 1980-an yang mengakibatkan pertambahan volume limbah industri termasuk limbah cair yang mengandung logam berat, diantaranya adalah cadmium (Kusumaya Et.al,2017). Kadar Cd di perairan alami berkisar antara 0,29-0,55 ppb dengan rata-rata 0,42 ppb. Dalam lingkungan alami yang bersifat basa, kadmium mengalami hidrolisis, teradsorpsi oleh padatan tersuspensi dan membentuk ikatan kompleks dengan bahan organik. Di perairan alami, Cd membentuk ikatan baik dengan ligan organik maupun anorganik. seperti $\mathrm{Cd}(\mathrm{OH})+$, $\mathrm{CdCl}+, \mathrm{CdSO} 4, \mathrm{CdCO} 3$ dan $\mathrm{Cd}$ organik (Sanusi, 2006). Berdasarkan KepMen LH No.51 Tahun 2004 konsentrasi Cd pada air nilai baku mutu yang telah ditetapkan yaitu 0,001 mg/L untuk Cd. Kadmium merupakan salah satu jenis logam berat yang berbahaya karena elemen ini beresiko tinggi terhadap pembuluh darah. (Wilkinson,1989).

\section{Kesimpulan}

Pada pengujian kualitatif ion $\mathrm{Cd}$ yang terdeteksi mengandung lohgam $\mathrm{Cd}$ adalah stasiun 3 yaitu pada sampel C1 dan C2. Dengan adanya hasil penelitian ini diharapkan para pemilik industry sadar dan melakukan pengolahan sebelum membuang air sisa produksi kesungai mengingat daerah kawasan industry sering mengalami banjir rob dan Kadmium merupakan salah satu elemen yang paling berbahaya bagi kesehatan manusia, karena menghasilkan efek buruk pada proses metabolisme Kadmium di klasifikasikan sebagai unsur yang bersifat toksik dengan waktu paruh pada rentang 10-30 tahun 94 dan dan diketahui dapat membuat kerusakan pada organ seperti ginjal, hati dan paru paru, walau dalam konsentrasi yang sangat kecil.

\section{Daftar Pustaka}

Cotton, Albert F dan Wilkinson, Geoffrey. 1989. Kimia Anorganik Dasar. Jakarta : UI Press

Darmono. 2001. Logam dalam Sistem Biologi Makhluk Hidup. Jakarta (ID): UI-Press

Heydari, S. 2014. Separation/Preconcentration and Determination of Trace Levels of Cadmium in Saffron Samples by Dispersive LiquidLiquid Based on Solidification of Floating Organic Drop Microextraction Coupled to UV-Vis Spectrophotometry. Canadian Chenical Transactions Journal ;2(1):22916466

Husnan, A., I. Widowati \& J. Suprijanto. 2012. Studi Kandungan Logam Berat $\mathrm{Pb}, \mathrm{Cu}, \mathrm{Cd}, \mathrm{Cr}$ Pada Kerang Simping (Amusium pleuronectes), Air, dan Sedimen di Perairan Wedung, Demak Serta Analisa Maximum Tolerable Intake pada Manusia. Jurnal Penelitian FPIK Undip. Vol. 1 (2); 35-44.

KepMen LH. 2004. Keputusan Menteri Negara Lingkungan Hidup No: 51 tahun 2004 tentang Baku Mutu Air Laut. Deputi Menteri Lingkungan Hidup: Bidang Kebijakan dan Kelembagaan L.H, Jakarta. hlm.11

Nawawi, I., \& dkk. 2015. Pengaruh Keberadaan Industri Terhadap Kondisi Sosial Ekonomi dan Budaya Masyarakat Desa Lagadar Kecamatan Marga Asih Kabupaten Bandung.Journal UPI Sosietas, 5 No 2.

Supriyatrini,Endang.2017.Kandungan logam berat Kadmium(Cd) dalam air,sedimen, dan jaringan lunak kerang hijau (Pernaviridis) Di perairan Sayung, Kabupaten Demak. Prosiding Seminar Nasional Hasil-Hasil Penelitian Perikanan dan Kelautan ke-VI Fakultas Perikanan dan Ilmu Kelautan Pusat Kajian Mitigasi Bencana dan 
Rehabilitasi Pesisir, Semarang : Universitas Diponegoro

Vogel. 1990. Analisis Kualitatif Makro dan SemiMikro. Jakarta: PT.Kalman Media Pustaka

Widiyanto, A. F., \& dkk. 2015. Polusi Air Tanah Akibat Limbah Industri dan Limbah Rumah Tangga. Jurnal Kesehatan Masyarakat,10 No.2, 246-254. Diambil dari http://journal.unnes.ac.id/artikel nju/kema s/3388.

Xiaodong W, Qiuling Y, Zhidong Y, Qingwen D. 2011. Determination of cadmium and copper in water and food samples by dispersive liquid-liquid microextraction combined with UV-vis spectrophotometry. Microchemical Journal. 2011; 97:249-254.

Yulianto, B; A. Santoso; R. Azizah; S. Yulina; E. Supriyantini \& L. Maslukah. 2011. Studi Kandungan Logam Berat Kadmium (Cd) pada Air, Sedimen, dan Kerang Darah (Anadara Granossa) Di Pantai Morosari, Kec. Sayung, Kabupaten Demak. Penelitian Hibah FPIK Undip, Semarang. 